\title{
The Efficiency of Intrauterine Irrigation of the Cavitated Drug Solutes in Patients with Endometrial Receptivity Disorders
}

\author{
Oxana Alexandrovna Melkozerova ${ }^{1}$, Evgeniy Yuryevich Gluchov ${ }^{2}$, \\ Nadezda Vasilyevna Bashmakova ${ }^{1}$, Guzel Nuchovna Chistyakova ${ }^{1}$, Alena Valeryevna Lvova ${ }^{1}$, \\ Anna Michaylovna Bogdanova ${ }^{2}$, Aigul Adipovna Giniyatova ${ }^{1}$, Olga Germanovna Barlit ${ }^{2}$ \\ ${ }^{1}$ Ural Research Institute of Maternity and Child Care Russian Ministry of Health, Ekaterinburg, Russia \\ ${ }^{2}$ Ural State Medical University Russian Ministry of Health, Ekaterinburg, Russia
}

\section{Email address:}

abolmed1@mail.ru (O. A. Melkozerova),9222241411@mail.ru (E.Y. Gluchov),dr@niiomm.ru (N. V. Bashmakova), guzel@niiomm.ru (G. N. Chistyakova), akropol.10b@mail.ru (A. V. Lvova),79122408573@yandex.ru (A. M. Bogdanova), ajgulka@mail.ru (A. A. Giniyatova), bar-lit@yandex.ru (O. G. Barlit)

\section{To cite this article:}

Oxana Alexandrovna Melkozerova, Evgeniy Yuryevich Gluchov, Nadezda Vasilyevna Bashmakova, Guzel Nuchovna Chistyakova, Alena Valeryevna Lvova, Anna Michaylovna Bogdanova, Aigul Adipovna Giniyatova, Olga Germanovna Barlit. The Efficiency of Intrauterine Irrigation of the Cavitated Drug Solutes in Patients with Endometrial Receptivity Disorders. Journal of Gynecology and Obstetrics.

Vol. 6, No. 4, 2018, pp. 98-107. doi: 10.11648/j.jgo.20180604.15

Received: June 6, 2018; Accepted: July 12, 2018; Published: September 17, 2018

\begin{abstract}
Evaluate the efficiency of intrauterine irrigation of cavitated low-frequency sonication drug solution in restoring of endometrial receptivity in patients with uterine infertility. 92 women with uterine infertility due to endometrial hypoplasia were examined in the dynamics of therapy including irrigation of the uterine cavity with cavitated low-frequency ultrasound with drug solutions. The control group consisted of 28 healthy fertile women. An ultrasound examination of the pelvic organs with color dopplerogragy, histological and immunohistochemical study of the endometrium was performed on the "implantation window" LH + 7, in dynamics before the start of therapy and in the next cycle after the end of treatment. After cavitation irrigation of the uterine cavity, $62(67.39 \%)$ women with infertility in the endometrial specimens had adequate vascularization of the stroma (before treatment, $36.95 \%, \mathrm{p}=0.017$, in control $78.57 \%$ ), in $68(73,91 \%)$ women - a decrease in the density of the stromal matrix, in $64(69.56 \%)$ - according to light microscopy data, mature pinopodia were determined (initially $28.26 \%, \mathrm{p}=0.0015$ ). On the background of therapy, the ratio of $E R \alpha$ / PR expression in the stroma of the implantation endometrium was normalized, which was characterized by the prevalence of the PR pool ( $1.01 \pm 0.34$ before treatment, $0.36 \pm$ 0.03 after therapy, $p=0.040$, in control $0.34 \pm 0.06, p>0.05$ ). The parameters of stromal expression of natural uterine killers CD56 + bright against the background of treatment in patients with infertility come in accordance with the indices of healthy fertile women (from $35.21 \pm 2.14$ cells in $1 / \mathrm{s}$ to $45.75 \pm 3.18$ cells $1 / \mathrm{s}$; in the control $47.8 \pm 2.13$ cells in $1 / \mathrm{s} ; \mathrm{p}>0.05$ ). A significant decrease in stromal expression of $\mathrm{CD} 3+$ is noted: $78.17 \pm 6.89$ cells in $1 / \mathrm{s}$ versus $23.83 \pm 3.63$ cells in $1 / \mathrm{s} ; \mathrm{p}=0.004$. The expression level of CD34 in the endometrial stroma after the treatment was significantly increased $(20.88 \pm 0.77$ cells in $1 / \mathrm{s}$ versus $33.83 \pm 3.63$ cells in $1 / \mathrm{s}, \mathrm{p}=0.035$ ). The use of $\mathrm{G}-\mathrm{CSF}$ cavitaion solutions for irrigation of the uterine cavity appears to be effective in restoring tissue and molecular endometrial receptivity in patients with uterine infertility due to endometrial hypoplasia.
\end{abstract}

Keywords: Uterine Infertility, Endometrial Hypoplasia, Cavitation Irrigation of Uterine Cavity, Granulocyte Colony-Stimulating Factor 


\section{Introduction}

Significant successes of reproductive medicine, achieved over the past decades, did not solve the problem of reducing the demographic resources of our country. According to the World Health Organization, the frequency of infertile marriages in Russia exceeds $15 \%$, which is considered a critical level for the reproduction of the nation's population [1-3]. With the introduction of assisted reproductive technologies, the paradigm of the leading factor of infertility has changed: the dominant position now occupies the uterine factor, which is up to $62 \%$ in the structure of the unreasonable causes of female infertility in the population of Russian women [4-5].

The violation of full implantation in the transfer of good quality embryos in connection with the non-receptive endometrium is the most significant cause of reproductive failures of ART, occupying up to $70 \%$ in their structure $[4,6]$. The focus of scientific interest in recent years is research devoted to the study of the receptivity of the endometrium in the pathology of implantation associated with infertility and habitual miscarriage of pregnancy.

The most serious problem is the lack of measures to influence the non-receptive endometrium. The methods described in the literature for improving the receptivity of the endometrium are scattered and have a very low evidence base. The problem of the susceptibility of the endometrium to drug factors is related to the lack of an application point for therapeutic effects [7-8]. The effectiveness of hormonal therapy of refractory endometrium (level of evidence C) is insufficient $42 \%-48 \%$ [9]. Drugs, that improve microcirculation and rheology of blood, act at the systemic level, without leading to significant improvements in reproductive outcomes.

Difficulties in drug treatment for patients with endometrial dysfunction associated with infertility are associated not only with a decrease in the susceptibility of the endometrium due to a change in the pattern of expression of its receptor proteins, but also due to damage to the terminal branches of the vasculature of the uterus, which impedes the delivery of active substances to the tissues. These circumstances determined the search for fundamentally different factors of influence on the non-receptive endometrium, as well as technologies for delivering medicinal substances to the affected tissues using physical energies.

The aim of the work is to study the effectiveness of intrauterine irrigation of cavitated low-frequency sonication drug solution in restoring of endometrial receptivity in patients with uterine infertility.

\section{Material and Methods of Investigation}

An open, prospective, randomized controlled study of 92 women with a uterine infertility form due to endometrial hypoplasia. The control group consisted of 28 healthy fertile women who did not have a history of miscarriages, who had an anamnesis of urgent labor through natural birth canals without deviating from the physiological course of pregnancy and labor, resulting in the birth of healthy children.

Criteria for inclusion in the study: reproductive age (18 40 years); uterine infertility factor due to endometrial hypoplasia; thickness of the endometrium is not more than 7 $\mathrm{mm}$ per day $\mathrm{LH}+7$ (the period of the supposed "implantation window"), normal coagulation.

Exclusion criteria: age less than 18 and over 40 years; oncological diseases, somatic pathology, in which pregnancy is contraindicated; Infertility not associated with endometrial hypoplasia.

The technology of ultrasound receipt provided for three courses of irrigation of the uterine cavity for five procedures each, conducted monthly. The first course of the procedures was performed in the early follicular phase on the 7-9th day of the menstrual cycle, as a sounded medium, a saline solution was used $-0.9 \%$ sodium chloride solution.

The third course was conducted starting 7 days after ovulation $(\mathrm{LH}+7)$, during the "implantation window". The medium Filgrastim ${ }^{\circledR}($ Reg. No. LSR-002698/10) at a dose of $300 \mu \mathrm{g} / \mathrm{ml}$ diluted in $200 \mathrm{ml}$ of a $5 \%$ dextrose solution was used as the medium. The dose of Filgrastim ${ }^{\circledR}$ in the prepared solution was $3 \mu \mathrm{g} / \mathrm{ml}$.

For irrigation, the Fotek AK-100-25 apparatus with an improved intrauterine tip AA 211 was used, excluding the tubular reflux of the drug substance during the procedure. The infusion rate of the drug is $100 \mathrm{ml} / \mathrm{min}$. The frequency of ultrasonic vibrations is $25 \mathrm{kHz}$, the duration of the procedure is 3-5 minutes.

This study was preceded by a scientific experiment on the study of the effect of ultrasonic waves of low frequency $(25$ $\mathrm{kHz}$ ) minutes on the stability of the molecules of the active substance of the preparation Filgrastim ${ }^{\circledR}$ - granulocyte colony-stimulating growth factor - using the mass spectrometry method on the ultra-high resolution quadrapolarity mass spectrometer maXis impact HD, Bruker Daltonik GmbH. Based on the protocol No. 74 of 27.04.2015, mass spectrometric analysis of the molecules of the active substances of the drug Filgrastim ${ }^{\circledR}$ before and after treatment with low-frequency ultrasound in the spectrum of the range $20-25 \mathrm{kHz}$ for 300 seconds indicates a stable state of the molecules and their absence of fragmentation against the background of ultrasound impact.

The endometrial examination was performed on the day of the alleged "implantation window" of $\mathrm{LH}+7$, determined from the urinary test for ovulation, in dynamics before the start of therapy and in the next cycle after the end of treatment.

Endometrial biopsy specimens for histological examination were fixed in $10 \%$ neutral formalin, enclosed in paraffin, sections $5 \mu \mathrm{m}$ thick and stained with hematoxylin and eosin. Microscopic examination was carried out on a Carl Zeiss Primo Star microscope (Germany).

For the IGH study, a two-step streptavidin-biotinperoxidase method was used, with antigen unmasking and using standard sets of monoclonal and polyclonal antibodies from Bond RTU Primary and DAKO, USA. On the paraffin 
sections, the following markers were detected using the standard standard antibodies with a preliminary unmasking of the antigens in the microwave oven using the appropriate standard antibodies: ER $\alpha$, clone 6F-11; PR, clone 16; p53, clone DO-7; bcl-2, clone 100 / D5; CD34 ${ }^{+}$, clone QBEnd / 10; $\mathrm{CD}^{+}$, clone $\mathrm{LN} 10 ; \mathrm{CD} 20^{+}$, clone $\mathrm{MJ} 1$; $\mathrm{CD} 56^{+}$, clone 1213C3, Ki67, clone SP6; polyclonal antibodies to CD138 ${ }^{+}$, p16, VEGF-A, VEGFR-1, CD62L, LIF-R, LIF, Noxa; GCSF, clone 2D10; HIF-1alpha, clone OZ12.

The reaction was carried out by the visualization system "Dako Cytomation". For visualization of primary antibodies, a beige-biotin detection system was used for the Super Sensitive Polymer-HPR Detection System (Biogenex).

Serial paraffin sections were used for immunohistochemical studies. The results of the reaction of the receptors to estrogens and progesterones were identified by nuclear or membrane staining of the cells for the respective markers with an estimate of the percentage of stained cells and the intensity of the cell staining. Expression of receptors for estrogens and progesterones was assessed on a 3-point scale (weak, medium and severe degree). To analyze the results of IHC reactions, the method of histological counting of $\mathrm{H}$-score was used according to the formula: $\mathrm{HS}=1 \mathrm{a}+2 \mathrm{~b}+3 \mathrm{c}$, where $\mathrm{a}-\%$ of weakly stained cells, b - $\%$ moderately stained cells, c - $\%$ strongly colored cells, 1, 2, 3 - Intensity of staining, expressed in points.

To estimate the level of expression of Ki-67, bcl-2, p16, NOXA antigens in glands, indices of proliferation and apoptosis were calculated - the ratio of the number of stained cell nuclei to the total number of nuclei in percent when counting at least 400 nuclei. The expression of $\mathrm{Ki}-67$, bcl-2, p16, NOXA in the stroma was estimated by counting the number of stained nuclei in the field of view at an increase of 400 , and at least 10 fields of vision were studied. $\mathrm{CD}^{+}$, $\mathrm{CD} 20^{+}, \mathrm{CD}^{+} 6^{+}, \mathrm{CD}_{138^{+}}$expression was assessed by counting positive cells in the field of view at 400 magnification while counting at least 10 fields of vision.

Expression of CD34 ${ }^{+}$, HIF-1 $\alpha$, VEGF-A and VEGF-R1 was determined in epithelium, endometrial stroma and vascular endothelium. Activity manifested itself in the form of membrane staining and cytoplasm of epithelial and endothelial cells.

Expression of CD62L, LIF and LIF-R was determined on the membranes of surface epithelial cells of endometrial glands by counting the number of stained cells in the field of vision at an increase of 400, with at least 10 fields of vision being studied.

Statistical analysis of the data was carried out using the Statistica 7.0 application software package. The results were processed using variational statistics and presented in the form $\mathrm{M} \pm \mathrm{m}$. Evaluation of the reliability of differences in mean values and relative indicators was carried out using the t-test (Student's test). For the level of significance in the study, $\mathrm{P}<0.05$ is accepted. The differences between the nonparametric variables were carried out using Pearson's $\chi 2$ (Person). Relative risk was assessed by odds ratio (OR) with a $95 \%$ confidence interval $(95 \%$ CL). The null hypothesis was rejected at $\mathrm{p}<0.05$.

\section{Results}

The average age of the examined women was $33.13 \pm 0.72$ years in the main group and $32.52 \pm 0.68$ years in the control group; $p>0.05$. The groups were comparable in age.

The main nosology that forms the clinical picture of the uterine form of infertility associated with the "thin" endometrium was chronic endometrium, verified in $68.47 \%$ of observations. Chronic endometritis was often combined with inflammatory diseases of the lower part of the reproductive tract $(56.52 \%$ vs. $7.14 \%$ in the control, $\mathrm{p}=$ $0.04)$. About one third of patients in the main observation group (28.26\%) suffered from chronic adnexitis and had a history of sexually transmitted infections. The structure of organic lesions of the uterus, leading to impaired fertility, was represented by Asherman's syndrome in $23.91 \%$, malformations of the uterus (7.69\%).

A peculiarity of the obstetric anamnesis of patients with infertility associated with the "thin" endometrium is the dominance of secondary infertility (67.39\% of women). In this case, only one third of patients of the first group $(35.48 \%)$ had infertility secondary to infertility. Mainly secondary infertility was preceded by a series of medical abortions of undeveloped pregnancies (an average of $2.46 \pm$ 0.54 abortions), or spontaneous abortions (an average of 1.86 \pm 0.56 abortions per patient in this group).

According to the history, the dominant position in the structure of reproductive losses in patients of the main observation group belongs to the undeveloped pregnancy $(63.83 \%)$, which can be considered one of the clinical manifestations of endometriopathy. A high incidence of surgical abortion in anamnesis in patients with infertility (40.21\%) associated with a "thin" endometrium is indicated. Auxiliary reproductive technologies were used by $69.56 \%$ of patients of the main group. The number of attempts of IVF, undertaken by women with infertility and endometrial hypoplasia, reached 6 , which indicates the absence of the effect of ART programs in these patients. $45.65 \%$ of the patients in the main group belonged to the recurrent implantation failure category and had 2 or more unsuccessful IVF attempts.

One of the primary control criteria for the effectiveness of treatment in our study was a change in the thickness of the endometrium after treatment. In women of the main group after the 3 courses of LFU of the uterine cavity the average M-echo index increased significantly with ME $6.0(5.5 \div 6.3)$ $\mathrm{mm}$ to $\mathrm{ME} 8.6(8.4 \div 8.7) \mathrm{mm}, \mathrm{p}<0.05$, and became statistically indistinguishable from the control ME values of $8.2 \mathrm{~mm}(7.8 \div 8.64), \mathrm{p}>0.05$. In this case, normalization of the thickness of the endometrium (more than $7 \mathrm{~mm}$ ) in the main group was observed in $93.8 \%$ of patients, which significantly exceeded the results of other treatment methods given in the literature [4-5].

After the treatment, the patients of the main group showed a significant decrease in the frequency of the abnormal 
sonographic picture of the endometrium after the first course of procedures for irrigation of the uterine cavity with cavitated solutions - a non-uniform endometrial picture was statistically significantly less $(76.6 \%$ before treatment and $43.8 \%$ after first course, $\mathrm{p}<0.05)$, hyperechoic inclusions in the basal layer $(79.7 \%$ and $42.2 \%$, respectively, $\mathrm{p}<0.05)$. After third course of procedures, the normal picture was determined in $80.9 \%$ of cases.

Improvement of blood circulation in the vascular tree of the uterus is a necessary condition for restoring the receptivity of the endometrium. As a result of therapy in women of the main group, the visualization of the uterine vessels during CDC (basal arteries - from 75\% and spiral arteries - from $53.1 \%$ to $100 \%, \mathrm{p}=0.001$ ), statistically significantly decreased the pulsation index in the uterine arteries.

Hysteroscopic signs of CE after 3 courses of procedures for cavitation irrigation of the uterine cavity were revealed in the main group in 10 patients $(15.6 \%$ versus $42.2 \%$ before treatment, $\mathrm{p}=0.001)$.
The analysis of the morphological picture of the endometrium in the dynamics of therapy with the use of cavitation irrigation of the uterine cavity with the solution of the granulocyte colony-stimulating factor established the restoration of synchronization of the maturation of endometrial glands in the middle secretory phase of the menstrual cycle in the majority $(82.61 \%)$ of the samples of the implantation endometrium of the main group of women, which is indistinguishable from of the control values of $74.42 \%(p>0.05)$, whereas before treatment, only $57.77 \%$ of the endometrial specimens were histologically consistent with the mean stage of secretion (Table 1).

In patients of the main group, the frequency of verification during the "implantation window" of endometrial specimens with glands in the proliferation stage decreased to $10.86 \%$, compared to $37.03 \%$ before treatment, $\mathrm{p}=0.016$. This indicates normalization of systemic and paracrine regulation of the interaction of the stromal and glandular components of the endometrium against the background of complex therapy.

Table 1. Morphological characteristics of endometrium in patients with infertility due to endometrial hypoplasia in the dynamics of therapy, LG $7^{+},(\%, \chi 2, p)$

\begin{tabular}{|c|c|c|c|c|c|c|c|}
\hline & & $\begin{array}{l}\text { Before treatment } \\
\text { n=92 } \\
\text { P\% } \pm \text { m / abs. N0 }\end{array}$ & $\begin{array}{l}\text { After treatment } \\
\text { n=92 } \\
\text { P\% } \pm \text { m / abs. N0 }\end{array}$ & $\begin{array}{l}\text { Control } \\
\mathrm{n}=\mathbf{2 8} \\
\mathbf{P} \% \pm \mathrm{m} / \text { abs.N0 }\end{array}$ & $\chi^{2} / \mathbf{p}$ & & \\
\hline & & 1 & 2 & 3 & $\chi^{2} / \mathbf{p}_{1-2}$ & $\chi^{2} / \mathbf{p}_{1-3}$ & $\chi^{2} / \mathbf{p}_{2-3}$ \\
\hline \multirow{2}{*}{1} & \multirow{2}{*}{ Corresponds to the phase of the cycle } & $82.61 \pm 7.01 \%$ & $86.95 \pm 7.12 \%$ & $89.28 \pm 6.16 \%$ & 0.432 & 0.661 & 0.035 \\
\hline & & 38 & 40 & 25 & 0.243 & 0.416 & 0.849 \\
\hline \multirow{2}{*}{2} & \multirow{2}{*}{ Uniform distribution of glands } & $50.00 \pm 8.98 \%$ & $73.91 \pm 8.08 \%$ & $81.14 \pm 7.61 \%$ & 4.329 & 6.331 & 0.058 \\
\hline & & 23 & 34 & 23 & 0.012 & 0.011 & 0.758 \\
\hline \multirow{2}{*}{3} & Glands in late proliferation: marked & $37.03 \pm 3.71 \%$ & $10.86 \pm 3.64 \%$ & $10.71 \pm 5.22 \%$ & 6.423 & 6.745 & 0.224 \\
\hline & chronometric lag & 17 & 5 & 3 & 0.016 & 0.016 & 0.217 \\
\hline \multirow{2}{*}{4} & Glands in early secretion: moderate & $28.26 \pm 8.71 \%$ & $21.73 \pm 7.82 \%$ & $21.42 \pm 8.15 \%$ & 0.822 & 0.269 & 0.095 \\
\hline & chronometric lag & 13 & 10 & 6 & 0.251 & 0.603 & 0.876 \\
\hline \multirow{2}{*}{5} & Glands in the middle secretion phase: & $71.73 \pm 8.07 \%$ & $82.61 \pm 8.16 \%$ & $74.42 \pm 8.59 \%$ & 0.961 & 0.035 & 1.235 \\
\hline & chronometric compliance & 33 & 38 & 20 & 0.327 & 0.847 & 0.127 \\
\hline \multirow{2}{*}{6} & Glands in late secretion: moderate & $17.39 \pm 7.01 \%$ & $8.69 \pm 2.75 \%$ & $10.71 \pm 6.39 \%$ & 3.019 & 0.596 & 0.748 \\
\hline & chronometric advance & 8 & 8 & 3 & 0.082 & 0.45 & 0.749 \\
\hline \multirow{2}{*}{7} & \multirow{2}{*}{ Mellow stroma } & $21.73 \pm 7.42 \%$ & $73.91 \pm 7.18 \%$ & $85.71 \pm 6.96 \%$ & 14.327 & 16.286 & 1.545 \\
\hline & & 10 & 34 & 24 & 0.001 & 0.001 & 0.083 \\
\hline \multirow{2}{*}{8} & \multirow{2}{*}{ Dense stroma } & $69.56 \pm 8.32 \%$ & $23.91 \pm 8.85 \%$ & $10.71 \pm 6.16 \%$ & 12.323 & 19.924 & 0.364 \\
\hline & & 32 & 11 & 3 & 0.002 & 0.0001 & 0.696 \\
\hline \multirow{2}{*}{9} & \multirow{2}{*}{ Vessels of the stroma narrowed } & $21.73 \pm 7.42 \%$ & $13.04 \pm 5.14 \%$ & $7.14 \pm 1.32 \%$ & 1.832 & 2.371 & 0.043 \\
\hline & & 10 & 6 & 2 & 0.078 & 0.123 & 0.873 \\
\hline \multirow{2}{*}{10} & \multirow{2}{*}{ Severe vascular component of the stroma } & $36.95 \pm 8.65 \%$ & $67.39 \pm 6.16 \%$ & $78.57 \pm 8.15 \%$ & 6.627 & 9.638 & 0.147 \\
\hline & & 17 & 31 & 22 & 0.011 & 0.0019 & 0.798 \\
\hline \multirow{2}{*}{11} & \multirow{2}{*}{ Presence of pinopodia } & $28.26 \pm 7.52 \%$ & $69.56 \pm 8.84 \%$ & $82.14 \pm 7.6 \%$ & 6.607 & 11.124 & 0.807 \\
\hline & & 13 & 32 & 23 & 0.015 & 0.008 & 0.636 \\
\hline \multirow{2}{*}{12} & \multirow{2}{*}{ Endometrial polyps } & $21.73 \pm 7.42 \%$ & $10.86 \pm 5.16 \%$ & $17.85 \pm 7.61 \%$ & 1.238 & 0.101 & 1.768 \\
\hline & & 10 & 5 & 5 & 0.256 & 0.749 & 0.174 \\
\hline \multirow{2}{*}{13} & \multirow{2}{*}{ Chronic endometritis } & $32.61 \pm 8.32 \%$ & $6.52 \pm 3.16 \%$ & $7.14 \pm 2.1 \%$ & 11.578 & 5.137 & 0.567 \\
\hline & & 15 & 3 & 2 & 0.001 & 0.013 & 0.878 \\
\hline
\end{tabular}

* With regard to the Bonferoni amendment. when comparing three observation groups. differences at a significance level of $\mathrm{p}<0.017$ are considered reliable.

The most important effect of ultrasonic cavitation therapy is its effect on the stroma of the endometrium. After cavitation irrigation of the uterine cavity. $73.91 \%$ of women with infertility managed to reduce the density of the stromal matrix of the endometrium. which is important in the secretory remodeling of the endometrium during the "implantation window". Friable stromal fibers had uniform vascularization in the endometrial specimens of the major groups with good vascular clearance and a uniform distribution of glands in the secretion stage. In $67.39 \%$ of women with infertility on the background of ultrasonic cavitation therapy in the endometrial specimens. an adequate vascularization of the stroma was noted (before treatment $36.95 \%$. $\mathrm{p}=0.017$. in control $78.57 \%$ ).

The pronounced narrowing of the stroma vessels. the depletion of the stromal matrix by the vascular component. 
signs of vascular sclerosis were noted much more rarely after complex therapy - in $13.69 \%$ of women with infertility (before treatment $-21.73 \%$. respectively).

The effect of complex therapy using ultrasonic cavitation irrigation of the uterus cavity also touched the markers of tissue receptivity of the endometrium. There was a significant increase in the pool of mature pineapodia in endometrial specimens detected by light microscopy data during the "implantation window" in women with infertility compared with the initial picture before treatment $(69.56 \%$ vs baseline $28.26 \%$. $\mathrm{p}=0.0015)$.

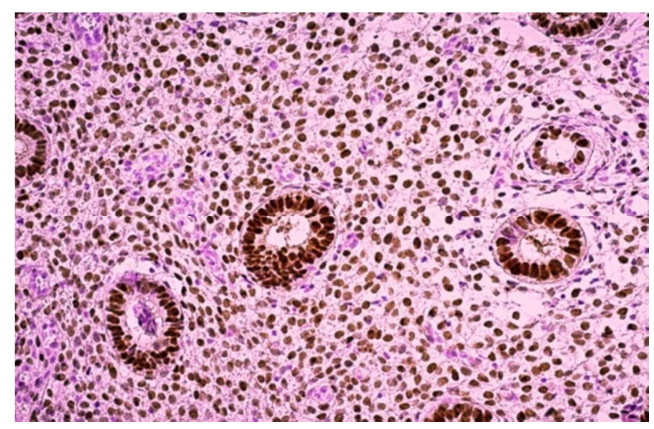

Figure 1. Before treatment: Intensive nuclear expression of ER $\alpha$ with glands and stroma of the implantation endometrium $(L G 7+)$. which is observed when the endometrial receptivity is impaired. Light microscopy; magnification $x 400$.

In a comparative analysis of the tissue receptor status of patients with reproductive failures associated with endometrial hypoplasia. a number of positive aspects related to changes in endometrial steroid receptors in observation groups are noteworthy in the dynamics of therapy. Normalization of the ER $\alpha$ pool in the stroma and endometrial glands in the middle luteal phase of the cycle was observed in all the observation groups to a level statistically corresponding to the control values (Table 2). In this case. after treatment. significant differences in the expression level of ER $\alpha$ in the glands of the implantation endometrium of infertile patients disappeared after treatment: $231.09 \pm 8.76$ points. against $198.47 \pm 18.68$ points in the control. $\mathrm{p}=0.044$ to treatment and $222.78 \pm 14.22$ points against $198.47 \pm$ 18.68 in the control. $\mathrm{p}>0.05$. after therapy (Figure 1. 2).

Due to this. the ratio of ER $\alpha$ / PR expression in the stroma of the implantation endometrium has been normalized in these patients. which is characterized by a predominance of the progesterone receptor pool (Fig. 2).

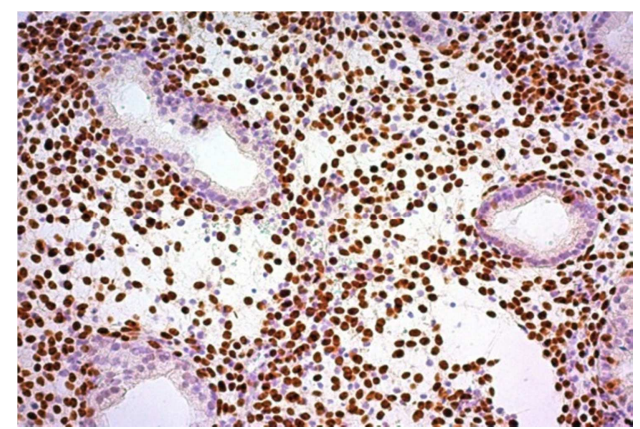

Figure 2. After therapy: the correct pattern of $P R$ expression in the implantation endometrium: intensive expression of $P R$ in stromal nuclei and disappearance of $P R$ expression in the endometrial gland nuclei (cycle day $L G 7+$ ). Light microscopy. magnification $x 400$.

This indicator. which significantly exceeded the control values before treatment $(1.01 \pm 0.34$ before treatment. compared with $0.34 \pm 0.06$ in the control. $\mathrm{p}=0.040$ ). after therapy statistically corresponds to the parameters of the control group $(0.36 \pm 0.03$ against $0.34 \pm 0.06$ in the control. $\mathrm{p}>0.05)$. The same trend is noted in the endometrial glands of the main observation group; however. there are no significant differences in the parameters in the dynamics of therapy (Table 2).

Table 2. Immunohistochemical parameters of expression of cellular and molecular markers of the receptive function of the endometrium in women with uterine infertility due to endometrial hypoplasia in the dynamics of therapy $(M \pm m ; p)$

\begin{tabular}{|c|c|c|c|c|}
\hline \multirow{2}{*}{ Parameters } & \multicolumn{2}{|c|}{ Main group: Patients with uterus infertility $(n=92)$} & \multirow{2}{*}{$\begin{array}{l}\text { Control group } \\
(n=28)\end{array}$} & \multirow{2}{*}{$\mathbf{p}$} \\
\hline & Before treatment & After treatment & & \\
\hline & 1 & 2 & 3 & \\
\hline $\mathrm{ER} \alpha$ in stroma. points of h-score & $117.19 \pm 10.05$ & $101.56 \pm 18.75$ & $95.53 \pm 15.30$ & NS \\
\hline $\mathrm{ER} \alpha$ in glands. points of h-score & $231.10 \pm 8.76$ & $222.78 \pm 14.22$ & $198.47 \pm 18.68$ & $\mathrm{p}_{1-3}=0.044$ \\
\hline PR in stroma. points of h-score & $265.48 \pm 5.13$ & $266.67 \pm 7.41$ & $263.47 \pm 17.13$ & NS \\
\hline PR in glands. points of h-score & $214.71 \pm 13.02$ & $231.00 \pm 21.06$ & $231.21 \pm 24.44$ & NS \\
\hline $\mathrm{ER} \alpha / \mathrm{PR}$ in stroma & $0.45 \pm 0.04$ & $0.32 \pm 0.08$ & $0.34 \pm 0.06$ & $\begin{array}{l}\mathrm{p}_{1-2}=0.042 \\
\mathrm{p}_{1-3}=0.040\end{array}$ \\
\hline $\mathrm{ER} \alpha / \mathrm{PR}$ in glands & $1.75 \pm 0.30$ & $1.08 \pm 0.48$ & $1.17 \pm 0.29$ & $\begin{array}{l}\mathrm{NS} \\
\mathrm{p}_{1-2}=0.001\end{array}$ \\
\hline $\mathrm{CD} 3^{+}$in stroma. cells in vision fields & $78.17 \pm 6.89$ & $23.83 \pm 3.63$ & $3.00 \pm 1.50$ & $\begin{array}{l}\mathrm{p}_{1-3}=0.000 \\
\mathrm{p}_{2-3}=0.003\end{array}$ \\
\hline $\mathrm{CD}^{+}$in glands. cells in vision fields & $50.56 \pm 4.61$ & $26.00 \pm 5.48$ & $11.00 \pm 1.53$ & $\begin{array}{l}\mathrm{p}_{1-2}=0.021 \\
\mathrm{p}_{1-3}=0.015\end{array}$ \\
\hline CD $20^{+}$in stroma. cells in vision fields & $25.71 \pm 5.42$ & $2.75 \pm 0.26$ & $0.80 \pm 0.41$ & $\begin{array}{l}\mathrm{p}_{1-2}=0.031 \\
\mathrm{p}_{1-3}=0.015\end{array}$ \\
\hline $\mathrm{CD} 20^{+}$in glands. cells in vision fields & $6.13 \pm 1.32$ & $2.52 \pm 0.29$ & $3.00 \pm 1.47$ & NS \\
\hline $\mathrm{CD} 56^{+}$in stroma. cells in vision fields & $35.21 \pm 2.14$ & $45.75 \pm 3.18$ & $47.8 \pm 2.13$ & $\mathrm{p}_{1-2}=0.032$ \\
\hline $\mathrm{CD} 56^{+}$in glands. cells in vision fields & $7.32 \pm 1.12$ & $17.28 \pm 2.32$ & $14.56 \pm 2.14$ & $\mathrm{p}_{1-5}=0.035$ \\
\hline $\mathrm{CD} 138^{+}$in stroma. $\%$ of colored cells & $21.81 \pm 3.41$ & $7.23 \pm 2.78$ & 0 & $\mathrm{p}_{1-2}=0.035$ \\
\hline
\end{tabular}




\begin{tabular}{|c|c|c|c|c|}
\hline \multirow{2}{*}{ Parameters } & \multicolumn{2}{|c|}{ Main group: Patients with uterus infertility $(n=92)$} & \multirow{2}{*}{$\begin{array}{l}\text { Control group } \\
(\mathrm{n}=28)\end{array}$} & \multirow[b]{2}{*}{$\mathbf{p}$} \\
\hline & Before treatment & After treatment & & \\
\hline & 1 & 2 & 3 & \\
\hline G-CSF in stroma. points of h-score & $116.45 \pm 11.94$ & $125.00 \pm 16.83$ & $128.33 \pm 22.63$ & NS \\
\hline 1 & 2 & 3 & 4 & 5 \\
\hline G-CSF in glands. points of $\mathrm{h}$-score & $232.74 \pm 10.19$ & $226.67 \pm 16.22$ & $258.80 \pm 12.20$ & NS \\
\hline Ki 67 in stroma. \% of colored cells & $26.60 \pm 3.10$ & $23.00 \pm 1.20$ & $34.00 \pm 5.08$ & NS \\
\hline Ki 67 in glands. $\%$ of colored cells & $64.44 \pm 8.41$ & $55.00 \pm 10.76$ & $75.00 \pm 19.06$ & NS \\
\hline p 53 in stroma. \% of colored cells & $34.86 \pm 5.68$ & $53.00 \pm 2.12$ & $81.81 \pm 7.61$ & $\begin{array}{l}\mathrm{p}_{1-2}=0.034 \\
\mathrm{p}_{1-3}=0.015\end{array}$ \\
\hline $\begin{array}{l}\text { p } 53 \text { in glands. } \% \text { of colored cells } \\
\text { bcl } 2 \text { in stroma. } \% \text { of colored cells }\end{array}$ & $\begin{array}{l}59.29 \pm 7.08 \\
27.50 \pm 3.73\end{array}$ & $\begin{array}{l}72.00 \pm 8.01 \\
14.38 \pm 1.63\end{array}$ & $\begin{array}{l}93.83 \pm 1.23 \\
12.25 \pm 3.59\end{array}$ & $\begin{array}{l}\mathrm{p}_{1-3}=0.025 \\
\text { NS }\end{array}$ \\
\hline bcl 2 in glands. $\%$ of colored cells & $62.38 \pm 4.06$ & $22.33 \pm 4.32$ & $23.00 \pm 3.07$ & $\begin{array}{l}\mathrm{p}_{1-2}=0.004 \\
\mathrm{p}_{1-3}=0.009\end{array}$ \\
\hline NOXA in glands. points of h-score & $254.19 \pm 8.12$ & $234.44 \pm 15.94$ & $274.44 \pm 13.31$ & NS \\
\hline LIF in glands. points of h-score & $120.00 \pm 5.90$ & $143.33 \pm 6.20$ & $132.22 \pm 10.19$ & $\mathrm{p}_{1-2}=0.047$ \\
\hline LIF-R in stroma. points of h-score & $67.74 \pm 10.92$ & $103.75 \pm 8.49$ & $85.56 \pm 19.31$ & $\begin{array}{l}\mathrm{p}_{1-2}=0.001 \\
\mathrm{p}_{1-3}=0.022\end{array}$ \\
\hline LIF-R in glands. points of h-score & $123.55 \pm 12.02$ & $140.00 \pm 18.09$ & $165.56 \pm 23.16$ & $\mathrm{p}_{1-3}=0.043$ \\
\hline $\mathrm{CD}$ 62-L in glands. points of h-score & $207.07 \pm 11.70$ & $235.00 \pm 11.84$ & $171.29 \pm 19.41$ & $\mathrm{p}_{2-3}=0.003$ \\
\hline $\mathrm{CD} 34^{+}$in stromal endothelium. cells in vision fields & $20.88 \pm 0.77$ & $33.83 \pm 3.63$ & $37.99 \pm 1.23$ & $\begin{array}{l}\mathrm{p}_{1-2}=0.035 \\
\mathrm{p}_{1-3}=0.026\end{array}$ \\
\hline $\begin{array}{l}\text { VEGFR1 } \\
\text { in stroma. points of } \mathrm{h} \text {-score }\end{array}$ & $43.00 \pm 5.62$ & $25.44 \pm 9.59$ & $15.02 \pm 3.97$ & $\mathrm{p}_{1-3}=0.033$ \\
\hline $\begin{array}{l}\text { VEGFA } \\
\text { in stroma. points of } \mathrm{h} \text {-score }\end{array}$ & $216.00 \pm 9.05$ & $231.67 \pm 14.16$ & $268.00 \pm 10.38$ & $\mathrm{p}_{1-3}=0.018$ \\
\hline VEGFA/ VEGFR1 & $5.02 \pm 0.62$ & $14.62 \pm 0.68$ & $17.87 \pm 2.38$ & $\begin{array}{l}\mathrm{p}_{1-2}=0.008 \\
\mathrm{p}_{1-3}=0.013\end{array}$ \\
\hline HIF $1-\alpha$ in stroma. $\%$ of colored cells & $6.52 \pm 0.26$ & $6.43 \pm 0.46$ & $5.02 \pm 0.55$ & NS \\
\hline HIF $1-\alpha / C D 34$ & $1.18 \pm 0.52$ & $0.34 \pm 0.02$ & $0.27 \pm 0.03$ & NS \\
\hline
\end{tabular}

Concerning the presentation of immunocompetent cells in the implantation endometrium. there is a pronounced dynamics in the expression level of $\mathrm{CD}^{+} . \mathrm{CD} 20^{+} . \mathrm{CD}^{+} 6^{+}$. $\mathrm{CD}_{138^{+}}$on the background of therapy. There was a significant decrease in stromal $\mathrm{CD}^{+}$expression in the main observation group: from $78.17 \pm 6.89$ cells in vision field (vf) to $23.83 \pm 3.63$ cells in vf; $p=0.004$. At the same time. the reliability of the differences in these indicators relative to the control values is lost (Table 2). Similarly. against the background of treatment. there was a decrease in the level of $\mathrm{CD}^{+}$expression in the endometrial glands in the main observation group: from $50.56 \pm 4.61$ cells in vf up to 26.00 \pm 5.48 cells in vf; $p=0.021$. On the background of therapy. the stromal expression of $\mathrm{CD} 20^{+}$was reduced to a level corresponding to healthy fertile women (from $25.71 \pm 5.42$ cells in vf to $2.75 \pm 0.26$ cells in vf. $p=0.031$ ).

The parameters of stromal expression of natural uterine killers $\mathrm{CD}^{+} 6^{+}$bright against the background of treatment in patients with infertility come in line with the indices of healthy fertile women (from $35.21 \pm 2.14$ cells in vf to 45.75 \pm 3.18 cells in vf; in the control $47.8 \pm 2.13$ cells in vf; $p>$ 0.05). In the glands of the implantation endometrium. changes in the expression level of $\mathrm{CD}^{+} 6^{+}$on the background of therapy appear to be more pronounced. The statistically significant decrease in the expression level of $\mathrm{CD}^{2} 6^{+}$bright in the endometrial glands of infertile patients before initiation of therapy $(7.32 \pm 1.12$ cells in vf against $14.56 \pm 2.14$ cells in $v f$ in the control. $p=0.035)$ disappears by the time the treatment is completed $(17.28 \pm 2.32$ cells in vf compared to
$14.56 \pm 2.14$ cells in vf. $\mathrm{p}>0.05)$.

Against the background of therapy. there was a significant decrease in the expression of the marker of chronic endometritis $\mathrm{CD} 138^{+}$in the stroma of the endometrium of the main group of women. If $\mathrm{CD} 138^{+}$expression was detected before treatment in $73.33 \pm 13.28 \%$ of the endometrial samples of the main group of women. after the initiation of therapy. the detection rate of antibodies to $\mathrm{CD} 138^{+}$in this group was $11.11 \pm 7.12 \%$. indicating a significant decrease in this indicator $(\mathrm{p}=0.014)$.

There were no significant changes in the expression level of $\mathrm{M}-\mathrm{CSF}$ in the stroma and glands of the endometrium (Table 2).

There was no significant difference in the background of therapy in the expression of the Ki67 proliferation marker in the stroma and glands of the implantation endometrium in the patients of the main group.

The implantation process is always accompanied by activation in the glands. stroma. superficial epithelium and in the vessels of the endometrium of p53-dependent apoptosis [7. 10]. This physiological mechanism is estrogen-dependent and is regulated by the effect of ESR1 on bcl-2 transcription regulated by C-Jun proteins [11]. The biological meaning of this phenomenon during implantation is associated with the mobilization of endometrial cells for normal adhesion of the blastocyst and invasion of the trophoblast into the stroma and spiral arteries of the uterus.

In patients with infertility after ultrasonic cavitation irrigation of the uterine cavity. activation of p53-dependent apoptosis in the stroma of the endometrium was noted. In the 
glands of the implantation endometrium of the main observation group. the same tendency to activation of p53 dependent apoptosis was noted; however. the differences in valuesafter the therapy did not reach the level of reliability.

In patients of the main observation group. the dynamics of the expression of the protooncogenous inhibitor of apoptosis of bcl-2 in the stroma and glands of the implantation endometrium differed from the background of therapy. In the endometrial glands of patients with infertility. the expression level of the bcl-2 apoptosis inhibitor decreased almost 3-fold against the background of therapy (from $62.38 \pm 4.06$ to $22.33 \pm 4.32 \% . p=0.009)$. In the endometrial stroma. changes in bcl-2 expression in the dynamics of therapy are statistically insignificant (Table 2).

There was no significant change in the expression level of the NOXA protein in the implantation endometrium in the dynamics of therapy in women of the main observation groups.

In patients with infertility. the initially low LIF expression (Figure 3A. B) after therapy becomes significantly indistinguishable from the control group of women (initially $120.00 \pm 5.90$ points. in control $132.22 \pm 10.19$ points. $\mathrm{p}=$ 0.023 . after therapy. $143.33 \pm 6.20$ points. $p=0.047$ ).

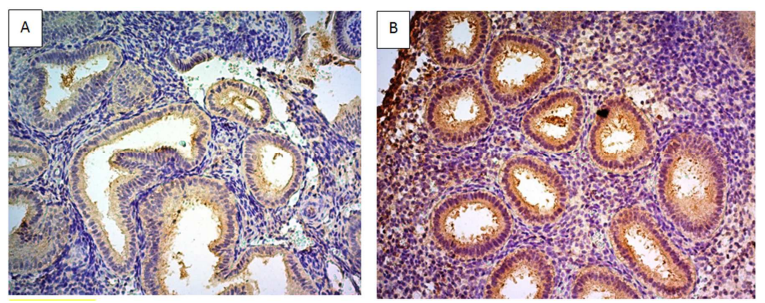

Figure 3. A. Before treatment: Weak cytoplasmic expression of LIF in the stroma and glands of the endometrium when its receptive properties are violated (cycle day LG7+). Light microscopy. Increase $x 400$.

B. After therapy: Significant cytoplasmic expression of LIF in the glands and stroma of the receptive endometrium (day of the LG7 + cycle); Light microscopy. magnification $\mathrm{x} 400$.

At the same time. in patients with infertility. a significant increase in stromal receptions of LIF-R (67.74 \pm 10.92 points against $103.75 \pm 8.49$ points. $p=0.001$ ) was noted against the background of therapy. In the endometrial glands of both observation groups. there was a positive trend towards an increase in LIF-R expression after therapy. but the LIF-R receptor fusion pool remained below the control values (Figure 4A. B).

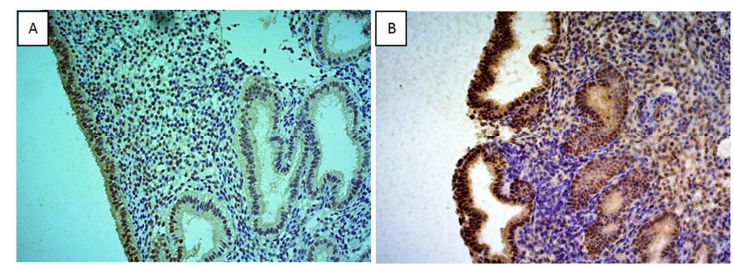

Figure 4. A. Before treatment: Weak and uneven expression of $L I F-R$ on the surface of endometrial glands and in stromal nuclei when endometrial receptivity is impaired (cycle day LG7+). Light microscopy. Increase $x 400$. $B$. After therapy: Intensive nuclear expression of LIF-R on the surface of the glands of the receptive endometrium (day of the $L G 7+$ cycle); Light microscopy; magnification $x 400$.
The results of the study confirm that one of the leading links in the pathogenesis of the development of "thin" refractory endometrium is the violation of vascular stromal remodeling and cytoangiarchitecture of the vascular tree of the uterus. In the study of $\mathrm{CD} 34^{+}$endothelial cell marker expression in implantation endometrium samples in the dynamics of therapy with the use of granulocyte colonimulating factor. its significant increase was noted in patients with infertility $(20.88 \pm 0.77$ cells in vf versus 33.83 \pm 3.63 cells in vf. $\mathrm{p}=0.035$ ). Initially low values of CD34 (Figure 5) in these patients after therapy corresponded to the level of control indices $(37.99 \pm 1.23$ cells in vf. $p>0.05)$.

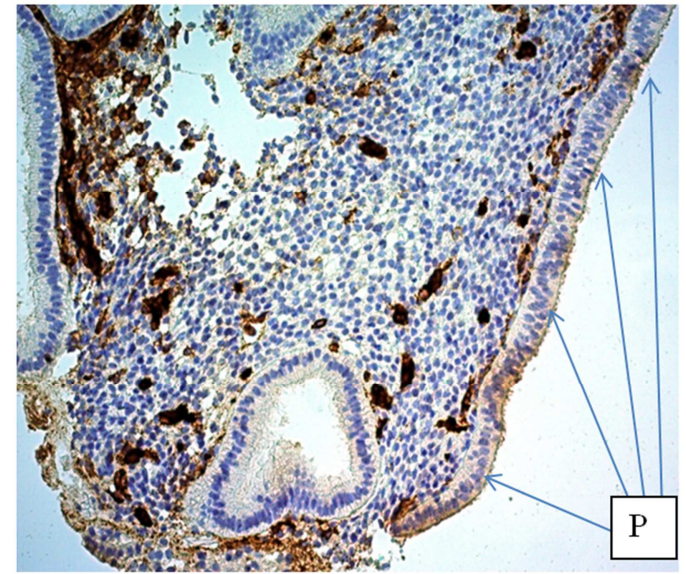

Figure 5. After therapy: intensive expression of the endothelial cell marker $C D 34$ in the stroma of the receptive endometrium $(L G 7+)$. Pinopodia $(P)$ are seen on the superficial epithelium; Light microscope; magnification $x$ 400 .

The endometrium of the women in the main observation group after therapy was less likely to express the antiangiogenic factor VEGFR-1. the reliability of the differences in the level of expression of which with the control values is lost after the therapy (Table 2). In the group of patients with infertility. the initially low expression of the activation factor of VEGF-A angiogenesis activation after the therapy became statistically indistinguishable from the control values $(216.00$ \pm 9.05 points before therapy. $231.67 \pm 14.16$ points after treatment and $268.00 \pm 10.38$ points in the control. $\mathrm{p}>0.05$ ).

The ratio of VEGF-A / VEGF-R1. which determines the angiogenic potential of endometrial tissue. had significant growth in the main group of the treatment in the course of therapy. approaching statistically to control values (from 5.02 \pm 0.62 to $14.62 \pm 0.68 . \mathrm{p}=0.08 .11 .22 \pm 2.95$ in the control). There were no significant changes in the level of HIF1 $\alpha$ expression in the endometrial stroma in the dynamics of therapy.

\section{Discussion}

Numerous experiments have shown that low-frequency ultrasound has a potentially important effect on the functional activity of cells. which can significantly affect tissue repair and regeneration processes in vivo. Low-frequency ultrasound causes dilatation of blood vessels and an increase 
in regional blood flow by 2-3 times. initiates favorable changes in the microcirculatory bed. and endothelium of the vessels. activates angiogenesis and the development of collateral blood flow [12-14]. American scientists Altland O.D. et al. (2004) for the first time published data on the NOdependent mechanism of vasodilation. which is due to the stimulation of NO synthase activity in the human endothelial cell line HUVEC in vitro under the influence of lowfrequency low-intensity ultrasound [15]. Fresh works by Japanese scientists Hanawa K. and Shindo T. et al. (2014) confirmed the activation of angiogenesis and an increase in the density of capillaries in cardiomyocytes when lowfrequency ultrasound was used. both in in vitro experiments (the LIPUS human endothelial cell line) and in the in vivo pig model [16-17]. Huang J. et al. (2015) showed that the activation of endothelial NO synthase in tissues under the influence of low-frequency ultrasound is the activation of the PI3K-Akt-eNOS cascade in endothelial cells [18].

A strategically important therapeutic effect of lowfrequency ultrasound in vivo is the phonophoretic effect. which ensures the delivery of the drug substance to the tissues. bypassing the central bloodstream. The foregoing effects of low-frequency ultrasound. as well as the impressive experience of using this method in surgery. traumatology. orthopedics. dentistry for the treatment of wound infection and chronic inflammatory processes. have determined our scientific interest in studying the possibilities of using ultrasound vibrations to restore the morphological structure and functional activity of "thin" refractory endometrium.

The choice of drug for ultrasonic cavitation is always determined by the clinical situation. The introduction of GCSF into the uterine cavity has already been described for the treatment of refractory endometrium [19]. The granulocyte colonimimulating factor activates the differentiation of endotemetrial polypotent stem cells and their proliferation. stimulates the release of angiogenic growth factors of $\mathrm{CD} 566^{\text {bright }+} \mathrm{CD} 16^{+}$by endometrial cells. On the other hand. it is known that the absorption capacity of the endometrium is extremely low due to the absence of lymphatic capillaries in its functional layer [21-22]. Therefore. the intrauterine route of administration of drugs. especially in the case of endometrial hypoplasia. has low bioavailability.

Low-frequency ultrasound. due to the physical effect of cavitation in a liquid medium. can be used as a transport of drug substance in the tissue. Cavitated solutions have a pronounced phonophoretic effect. which allows delivering medicinal substances into tissues to a sufficient depth. bypassing the central blood stream.

In our study. in patients with uterine infertility caused by endometrial hypoplasia. after therapy involving irrigation of the uterine cavity with a cavitated colony-stimulating factor solution. restoration of the normal morpho-functional structure of the endometrium was noted. which was manifested by synchronization of the secretory transformation of endometrial glands. decidualization of the stroma and adequate vascularization of it during the "implantation window". an increase in the pool of mature pineapodia on the apical surface of membranes of endometrial glands.

Initially. in patients with endometriopathy due to the course of chronic endometritis. according to our observations. there was a high incidence of sclerotic transformation of the stromal component and impoverishment of the vascular network of the functional layer of the endometrium. The process of loosening the stromal component of the secretory endometrium. which is the basis for its decidualization. necessary for adequate implantation of the blastocyst and subsequent invasion of trophoblast. was disrupted during the "implantation window" in more than $70 \%$ of patients. and was equally encountered in infertility and miscarriage. In parallel. there was a violation of the vascularization of the stromal matrix of the endometrium in patients with infertility and miscarriage of pregnancy on the background of endometrial hypoplasia. The "dense" nature of the stromal component of the "thin" endometrium with impoverishment of its vasculature. decreased activity of apoptosis probably underlies the difficulty of invading the cytotrophoblast into the spiral arteries of the uterus [22-23].

Ultrasonic cavitation therapy can reduce lymphocyticmacrophage infiltration of the stroma. activate the processes of neoangiogenesis. and change the density of the stromal matrix. bringing its morphological picture closer to the picture of the control tissues of the implantation endometrium.

According to our study. the ratio of stromal VEGF-A / VEGF-R1 expression. which determines the angiogenic potential of endometrial tissue. in the dynamics of cavitation therapy G-CSF had a significant increase. statistically approaching the control values. Large-scale studies by Japanese scientists in 2014-2016 on molecular mechanisms of angiogenesis activation under the influence of lowfrequency ultrasound have established a PI3K-Akt-eNOSdependent pathway for eNOS activation in endothelial cells [16. 17. 18]. The increase in the functional activity of endothelial cells is accompanied. according to our study. by a significant increase in the level of endothelial cell marker expression - $\mathrm{CD}_{3} 4^{+}$in implantation endometrial samples of infertile patients in the dynamics of cavitation G-CSF.

The main molecular effects of the granulocyte colonystimulating factor on the receptivity and functional activity of refractory endometrium in patients with infertility are associated with normalization of the $\mathrm{ER} \alpha$ pool in the stroma and endometrial glands. increasing to the level of control values of the expression of receptors for progesterone in the stroma of the endometrium. normalization of the expression ratio of ER $\alpha$ / PR in the stroma of the endometrium. Against therapy. there was a significant decrease in stromal expression of $\mathrm{CD}^{+}$. $\mathrm{D} 20^{+}$to a level corresponding to healthy fertile women.

Change in vascular architectonics of the endometrium on the background of cavitation therapy with G-CSF solution was accompanied by activation of recruitment of natural killers from peripheral blood to the endometrium. In women 
with infertility. There was an increase in the expression of CD56 ${ }^{\text {bright }}+$ in the stroma of the endometrium. Finally. Against a background of complex therapy. There was a significant decrease in the expression of the marker of chronic endometritis $\mathrm{CD}_{138^{+}}$in the stroma of the endometrium in patients of the main groups.

The endometrium of the patients of the main observation group after therapy showed a moderate increase in the level of cytoplasmic expression of the factor inhibiting leukemia (LIF) in the stroma and glands. as well as a significant increase in stromal receptivity of its LIF-R receptor.

\section{Conclusion}

Difficulties in treatment for patients with endometrial dysfunction are associated not only with a decrease in the sensitivity of the endometrium due to a change in the expression of sex steroid receptor's pattern. but also due to damage to the terminal branches of the uterus vasculature. which impedes the delivery of active substances to the tissues. These circumstances determine the need to find fundamentally different factors affecting the endometrium. as well as technologies for delivering medicinal substances to the affected tissues with the use of physical energies.

Summarizing the study. it can be recognized that the described positive changes in the morpho-functional state. tissue and molecular parameters of the receptivity of the endometrium testify to the effectiveness of ultrasonic irrigation technology of the uterine cavity with cavitated solutions in the complex therapy of patients with a uterine infertility caused by a refractory "thin" endometrium.

\section{References}

[1] The European health report 2015. Targets and beyond reaching new frontiers in evidence. Copenhagen: WHO Regional Office for Europe. 2015. Accessed July 08. 2018. http://www.euro.who.int/en/data-andevidence

[2] Health-2020: a European policy framework and strategy for the 21st century. Copenhagen: WHO Regional Office for Europe; 2013. Accessed July 08. 2018. http://www.euro.who.int/en/publications/abstracts/health2020-a-european-policy-framework-and-strategy-for-the21 stcentury

[3] Ermolenko. K. S. Radzinskij V. E. Rapoport S. I. The current state of the problem of the realization of the fertile function of women of late reproductive age. [Klinicheskaya medicina]. 2016; 94(1):10-15. (In Russ.). Accessed July 08. 2018. http://www.medlit.ru/journalsview/clinicalmedicine/view/jour $\mathrm{nal} / 2016 /$ issue-1/69-sovremennoe-sostoyanie-problemyrealizacii-fertil-noy-funkcii-zhenschin-pozdnegoreproduktivnogo-vozrasta

[4] Register ART RAHR. Report for 2016. SP-b; 2017. (in Russ.). Accessed July 08. 2018. http://www.rahr.ru/d_registr_otchet/registr_BRT_RARCH16.p df

[5] Valdes CT. Schutt A. Simon C. Implantation failure of endometrial origin: it is not pathology. but our failure to synchronize the developing embryo with a receptive endometrium. Fertil Steril. 2017 Jul; 108(1):15-18. https://doi.org/10.1016/j.fertnstert.2017.05.033

[6] Boyarskij K. YU. Gajdukov S. N. Pal'chenko N. A. Modern view on the problem of receptivity and thin endometrium in ART programs. Literature review. [Problemy reprodukcii]. 2013; 4:3-7. (in Russ.). Accessed July 08. 2018. https://www.mediasphera.ru/issues/problemyreproduktsii/2013/4/031025-72172013411

[7] Uterine Endometrial Function. Editor of H. Kanzaki. Osaka: Springer; 2017.

[8] Molecular mechanisms of the reproductive system diseases. Editor of M. A. Pal'cev. SPb.: Eko-vektor; 2017. (in Russ.).

[9] Pregravid preparation: the clinical protocol. Editor of V.E. Radzinskij. M.: Status Praesens; 2016: 23-25. (in Russ.). Accessed July 08. 2018. https://praesens.ru/pregravidarnayapodgotovka-klinicheskiy-protokol-mezhdistsiplinarnoyassotsiatsii-spetsialistov-repr

[10] Krylova YU. M. Kvetnoj I. M. Ajlamazyan Eh.K. Receptivity of the endometrium: molecular mechanisms of regulation of implantation. [Zhurnal akusherstva i zhenskih boleznej]. 2013; 2: 63-74. https://doi.org/10.17816/JOWD663135-142

[11] Li Z. L. Ueki K. Kumagai K. Regulation of bcl-2 transcription by estrogen receptor-alpha and C-Jun in human endometrium. Med. Mol. Morphol. 2014; 47(1): 43-53. https://doi.10.1007/s00795-013-0043-y

[12] Ogata T. Ito K. Shindo T. Hatanaka K. Eguchi K. Kurosawa R. Kagaya Y. Monma Y. Ichijo S. Taki H. Kanai H. Shimokawa H. Low-intensity pulsed ultrasound enhances angiogenesis and ameliorates contractile dysfunction of pressure-overloaded heart in mice. PLoS One. 2017; 12(9):e0185555. https://doi.org/10.1371/journal.pone.0185555

[13] Wu S. Xu X. Sun J. Zhang Y. Shi J. Xu T. Low-Intensity Pulsed Ultrasound Accelerates Traumatic Vertebral Fracture Healing by Coupling Proliferation of Type H Microvessels. J Ultrasound Med. 2018 Jan 24. https://doi.org/10.1002/jum.14525

[14] Bogdanova AM. Glukhov E.Yu. Dicke G.B. Application of low-frequency ultrasound in the complex treatment of the hypoplastic variant of chronic endometritis. Obstetrics and gynecology. 2017; 2: 90-6. https://dx.doi.org/10.18565/aig.2017.2.90-6

[15] Altland O.D. Dalecki D. Suchkova V.N. Low-intensity ultrasound increases endothelial cell nitric oxide syntase activity and nitric oxide synthesis. J. Thromb. Haemost. 2004; 2:637-643. https://doi.org/10.1111/j.1538-7836.2004.00655.x

[16] Hanawa K. Ito K. Aizawa K. Low-intensity pulsed ultrasound induces angiogenesis and ameliorates left ventricular dysfunction in a porcine model of chronic myocardial ischemia. PLoS One. 2014; (9):8:104-863. https://doi.org/10.1371/journal.pone.0104863. eCollection 2014.

[17] Shindo T. Ito K. Ogata T. Low-Intensity Pulsed Ultrasound Enhances Angiogenesis and Ameliorates Left Ventricular Dysfunction in a Mouse Model of Acute Myocardial Infarction. Arterioscler. Thromb. Vasc. Biol. 2016; (36):6:1220-1229. https://doi.org/10.1161/ATVBAHA.115.306477 
[18] Huang J. I. A. Shi Y. O. Li R. L. Angiogenesis effect of therapeutic ultrasound on HUVECs through activation of the PI3K-Akt-eNOS signal pathway. Am. J. Transl. Res. 2015; (7):6:1106-1115. Accessed July 08. 2018. http://www.ajtr.org/files/ajtr0004723.pdf

[19] Cleicher N. Vidali A. Barad D.H. Successful treatment of unreceptive thin endometrium. Fertill Sterill. 2011; (95):6:2123-2137. https://doi.org/10.1093/humrep/des370

[20] Jerman L. F. Hey-Cunningham A. The role of the lymphatic system in endometriosis: a comprehensive review of the literature. J. Biol. Reprod. 2015; (92):3:64-66. https://doi.org/10.1095/biolreprod.114.124313
[21] Koukourakis M. I. Giatromanolaki A. Sivridis E. LYVE-1 immunohistochemical assessment of lymphangiogenesis in endometrial and lung cancer. J. Clin. Pathol. 2015; (58):2:202206. https://doi.org/10.1136/jcp.2004.019174

[22] Uterine Endometrial Function / Editor of H. Kanzaki. Osaka: Springer. 2017; 155 p. Accessed July 08. 2018. https://www.springer.com/gp/book/9784431559702

[23] Simón C. Giudice LC. The Endometrial Factor: A Reproductive Precision Medicine Approach. CRC Press. Apr 27. 2017. Accessed July 08. 2018.

https://www.crcpress.com/The-Essential-EndometriumHandbook-Current-Applications-in-Clinical-Medicine/SimonGiudice/p/book/9781498740395 